\title{
A sociolinguística e a questão da variação: um panorama geral
}

\section{RESUMO}

Thiago Soares de Oliveira so.thiago@ hotmail.com Instituto Federal Fluminense, Rio de Janeiro, Brasil.

\begin{abstract}
Esta pesquisa teórica objetiva analisar os contributos da Sociolinguística no que tange aos aspectos da variação, refletindo acerca da emergência dessa disciplina, inclusive seus métodos de pesquisa, e do tratamento da língua como prática social, valendo-se, para isso, da articulação entre os vários autores que estudam o tema, especialmente William Labov, pai da Teoria da Variação. Trata-se do tracejamento de um panorama geral a partir do qual se discutem os aspectos que tangem a relação entre língua e sociedade. Com isso, pretende-se fornecer aos estudantes incipientes um olhar introdutório a respeito da Sociolinguística de forma geral.
\end{abstract}

PALAVRAS-CHAVE: Linguística. Sociolinguística. Variação Linguística. 


\section{INTRODUÇÃO}

William Labov foi um dos principais autores a tratar da questão da variação linguística. Já em meados dos anos 60 do século XX, esse estudioso introduziu novas discussões acerca da heterogeneidade da língua, o que, mais tarde, serviria de base para a sedimentação de outras características dessa disciplina, considerada um ramo da Linguística.

Na verdade, além da questão da variação, a Sociolinguística, de forma geral, também se preocupa com os temas relacionados ao preconceito linguístico, mobilidade e estigma social. Dessa forma, justifica-se este trabalho com base não só na obra de Labov, mas também na de outros autores que, a partir da obra laboviana, puderam reforçar os conceitos sociolinguísticos. Além disso, é muito importante refletir sobre a variação, especialmente na época atual, quando gramáticos e linguistas se posicionam em lados antagônicos, como se não houvesse o respaldo da História da Linguística (WEEDWOOD, 2002; LYONS, 2011) no sentido de que tanto o primeiro quanto o segundo grupo pertencem à mesma área do conhecimento, mas com concepções diversas.

Considerando que é a fonte donde os dados são retirados o que de fato define a melhor metodologia a ser adotada e considerando, também, o objetivo de dar conta da análise dos contributos da Sociolinguística em relação à questão da variação linguística, adota-se a pesquisa bibliográfica, que será executada a partir de obras de linguistas, sociolinguistas e estudiosos das diversas áreas da linguagem. Em outras palavras, pretende-se fazer uma abordagem introdutória partindo da convergência e dos posicionamentos teóricos dos autores utilizados a fim de facilitar a iniciação do estudante no campo da Sociolinguística.

Por fim, fica o registro de que as contribuições labovianas são vastas e incomensuráveis para os estudos da língua, motivo pelo qual este artigo não tenciona esgotar nesta análise inicial as diversas abordagens possíveis acerca dos contributos teóricos sociolinguísticos.

\section{OBSERVAÇÕES SOBRE A ABORDAGEM PROCEDIMENTAL ADOTADA}

Inicialmente, este trabalho não pretende apenas compilar ou resenhar várias 
iniciantes nessa área delimitada dos estudos linguísticos a partir de alguns comentários inseridos ao longo do texto. Obviamente, esses trechos não estão referenciados por se tratar de uma visão do autor deste trabalho; os demais excertos, contudo, atribuem aos autores respectivos o crédito do pensamento que lhes é devido.

Nesse rumo, a escolha pela utilização de algumas obras introdutórias e de alguns dos primeiros trabalhos labovianos é uma opção metodológica. Aliás, o próprio Labov explorou seus trabalhos exaustivamente, publicando-os inúmeras vezes em periódicos e apresentando-os em congressos e palestras. Por esse motivo, não se pode pautar a originalidade e o ineditismo de um trabalho científico apenas pelo tema adotado, mas também pela abordagem proposta. Pretende-se, neste artigo, reduzir a aridez com que determinados assuntos pertencentes à Linguística são conduzidos, de modo que alguns dos principais pressupostos sociolinguísticos, que serão oportunamente apresentados, sejam bastante acessíveis aos alunos que pretendem adentrar nessa área de estudos.

Durante toda a pesquisa teórica, é agregado e incorporado um olhar do autor deste artigo, esperando contribuir para a necessária e valiosa iniciação teórica discente que antecede ao aprofundamento na Sociolinguística. Logo, com um propósito bem definido, a condução do trabalho se torna mais fluida e relevante para a área, na medida em que propõe uma abordagem simplificada de alguns pilares sociolinguísticos. Dessa forma, decidiu-se pela tessitura dos seguintes tópicos: "considerações sobre a origem e o objeto da Sociolinguística Variacionista", "reflexões sobre a língua como prática social", "o estudo variacionista de Labov" e "o método sociolinguístico de pesquisa". Essa organização do trabalho e as obras dos autores foram metodicamente selecionadas com base no escopo pré-determinado, o que não desmerece, obviamente, outras possibilidades de escolha bibliográfica.

Enfim, dado o exíguo espaço de poucas laudas, é possível que alguns assuntos sejam mais aprofundados do que outros, mas nenhum deles foge à proposta delimitada. De qualquer forma, as referências ao fim do trabalho podem fornecer, juntamente com estes escritos, subsídios teóricos àqueles que se sentirem motivados a dar continuidade aos estudos sociolinguísticos, ajudando a compreender fenômenos e métodos de pesquisa dessa recente e relevante ciência. 


\section{BREVES CONSIDERAÇÕES SOBRE A ORIGEM E O OBJETO DA SOCIOLINGUÍSTICA VARIACIONISTA}

O termo Sociolinguística surgiu em meados dos anos de 1960, em um congresso organizado por William Bright na Universidade da Califórnia (Los Angeles). Nesse congresso, estavam presentes vários pesquisadores cujos estudos se voltavam para a relação entre linguagem e sociedade, como: John Gumperz, Einar Haugen, Dell Hymes, John Fisher, José Pedro Rona e William Labov. Inicialmente, a proposta de Bright (1974) para a Sociolinguística "era demonstrar a covariação sistemática das variações linguística e social, ou seja, relacionar as variações lingüísticas observáveis em uma comunidade às variações existentes na estrutura social desta mesma sociedade" (BRIGHT, 1974 apud ALKMIM, 2001, p. 28).

Para Bright (1974), a diversidade linguística seria o objeto de estudo da Sociolinguística, estando tal objeto relacionado a fatores tais como: identidade social do emissor ou falante, identidade social do receptor ou ouvinte, o contexto social e o "julgamento social distinto que os falantes fazem do próprio comportamento lingüístico e sobre os outros, isto é, as atitudes linguísticas" (ALKMIM, 2001, p. 29). Na verdade, foi a partir da atividade de pesquisadores da Antropologia Linguística, especialmente de Franz Boas e seus discípulos Edward Sapir e Benjamin Whorf, que a Sociolinguística se constituiu e nasceu "marcada por uma origem interdisciplinar" (ALKMIM, 2001, p. 29-30). Segundo Monteiro (2002), a língua é objeto de estudo de vários ramos do conhecimento, distinguindo-se pela forma de análise desse objeto. Entre as várias disciplinas que se aproximam do campo a que se dedica a Sociolinguística estão a Sociologia da Linguagem, a Etnografia da Comunicação, a Dialetologia, a Geografia Linguística e a Pragmática, cada qual com uma forma própria de abordar a língua.

É nesse ponto que, decerto, emergem dúvidas a respeito do que considerar como tratamento social da língua. Os diversos ramos das ciências, cada qual com metodologia e perspectiva próprias, possuem repertório teórico, reunindo-o de forma que possa ser utilizado futuramente. Ou, em contraste ou complementaridade a depender do caso, essas áreas do conhecimento se valem do próprio material armazenado para refutações e levantamento de dúvidas. Sabe-se que, a todo tempo, pilares do saber estão sendo construídos e 
desconstruídos por abordagens não só qualitativas, mas também quantitativas, estatísticas, ponto este que marca a relevância dos estudos variacionistas. Vide a exposição de Camacho (2001):

O exame da linguagem no contexto social é tão importante para a solução de problemas próprios da teoria da linguagem, que a relação entre língua e sociedade é encarada como indispensável, não mero recurso interdisciplinar. Como a linguagem é, em última análise, um fenômeno social, fica claro, para um sociolinguista, que é necessário recorrer às variações derivadas do contexto social para encontrar respostas para os problemas que emergem da variação inerente ao sistema linguístico (CAMACHO, 2001, p. 50).

A rigor, não só a variação linguística, mas também o "contato entre as línguas, questões relativas ao surgimento e extinção linguística, multilinguismo, [...] e mudança constituem temas de investigação na área" da Sociolinguística (MOLLICA, 2013, p. 10). Isso significa que, apesar de a variação ser o foco da vertente variacionista, a Sociolinguística, como um ramo amplo e fértil da Linguística, preocupa-se com diversos assuntos que cruzam língua e sociedade. Labov (2008) sintetiza o objeto da Sociolinguística como o estudo da língua falada em relação ao contexto social, partindo da comunidade linguística, entendida como o conjunto de indivíduos que, além de interagirem verbalmente, também compartilham um conjunto de normas relativas aos usos.

Sob esse prisma, desvincular o contexto social do contexto de uso língua é dar a ela um tratamento mecânico, desligado da realidade dos indivíduos que a manejam. Aliás, não seria possível dispensar um tratamento social à língua, tal com se propõe a Sociolinguística, já que a língua é construída ininterruptamente pela coletividade. Nesse sentido, ainda que não dispensáveis, análises linguísticas pautadas no idealismo de um idioma, e não em seu uso concreto, estão fadadas a não representar a realidade linguística. Obviamente, a análise de frases contextualmente deslocadas é útil ao reconhecimento de padrões e à determinação de normas, mas não corresponde verdadeiramente ao uso linguístico cotidiano.

\section{REFLEXÕES SOBRE A LÍNGUA COMO PRÁTICA SOCIAL}

A rigor, as normas são compiladas pela gramática normativa, acusada de perpetuar a noção de erro ${ }^{1}$, que é resultante "de visões de mundo, de juízos de 
valor, de crenças culturais, de ideologias" (Bagno, 2007a, p. 61), uma vez que, a língua, vista de dois lados, pode comportar duas ordens que se contrapõem: a primeira, relativa ao discurso científico, trabalha com noções de variação e mudança ${ }^{2}$; a segunda, firmada pelo senso comum, opera com a noção de erro e concepções já ultrapassadas, além de preconceitos sociais. Dessa forma, é necessário, para a investigação de dois pontos de vista díspares, recorrer à Sociolinguística, porque se trata de uma ciência interdisciplinar que não apregoa conceitos e discriminações que podem levar à exclusão social (BAGNO, 2007a).

Não obstante, não se pretende nem é prudente alijar do ensino de gramática os indivíduos que da língua fazem uso, uma vez que, na língua escrita ou falada, há padrões que, reconhecidos, facilitam o entendimento do idioma. Isso logicamente não significa que, no reconhecimento da norma, encerram-se as verdades de uso de um idioma, inclusive porque a escrita não reflete fidedignamente a fala, e vice-versa. Escrita e fala são dois modos a partir do qual é possível se expressar por meio do idioma. Há, então, lugar para convívio entre norma e uso? Basta quantificar dados e entender com se estrutura uso linguístico para que à língua seja conferido o devido trato social?

A princípio, é importante registrar que, mesmo com foco na fala, a Sociolinguística variacionista não exclui a escrita de suas possibilidades de análise, visto que nela a variação também pode se manifestar. O que significa, contudo, dizer que as línguas variam? Segundo Beline (2014), em sentido amplo, a variação pode ser pensada a partir das diferentes línguas que existem no mundo e, afunilando o foco para a análise de apenas um país (o Brasil, por exemplo), a partir das diferenças existentes na língua que, apesar de comportar a diversidade linguística, não impede a comunicação entre os falantes. Ainda que essa variação seja detectada no léxico do idioma, o que importa é que existe a possibilidade de referência a um mesmo objeto, fruta, planta, etc., pela utilização de vocábulos diversos. Além do léxico, a variação pode ocorrer a depender do lugar (variação diatópica) em que a língua é manejada, bem como da situação de formalidade de uso (variação diafásica), dentre outras.

Essa explicação sintética de Beline (2014) demonstra não só que existem várias formas possíveis de ocorrência de um vocábulo, mas também que as "atitudes linguísticas [...] são poderoso fator de evolução das línguas" (CALVET, 2002, p. 81). Aliás, Labov (2008) assevera que, em todos os níveis da língua, 
ocorre variação, seja fonético-fonológica, morfológica, sintática, semântica, lexical, estilístico-pragmática, mas registra que essa variação não é fortuita e sujeita ao caos, mas organizada e condicionada por fatores linguísticos e extralinguísticos. Quanto aos fatores linguísticos de condicionamento que asseguram a heterogeneidade ordenada da língua, Bagno (2007a) exemplifica com a análise da pronúncia das palavras raspa e rasga, explicando que:

\begin{abstract}
Na primeira palavra aparece um som [s], enquanto na segunda aparece um som [z], embora as duas se escrevam com a mesma letra s. Por quê? Muito simples: o s de raspa vem antes de um /p/, que é uma consoante surda, isto é, produzida sem a participação das pregas (ou cordas) vocais, e por isso o s se pronuncia como [s], que também é um som surdo. Já no caso de rasga, o s está diante de uma consoante sonora, o /g/ (produzida com a participação das pregas vocais), e por isso ele se realiza como um [z], que também é uma consoante sonora. É o contexto fonético, ou seja, a influência de uma consoante sobre a outra, que vai explicar, neste caso, a variação [s] - [z]. A sonoridade (ou vozeamento) de um fonema vai provocar a sonorização do outro; a não sonoridade (ou não vozeamento) de um fonema vai provocar a não sonorização do outro. Aqui estamos diante de um fenômeno de variação que está condicionado apenas linguisticamente (BAGNO, 2007a, p. 40-41).
\end{abstract}

Nota-se, assim, que essa ordenação pode ser explicada, reforçando que o "pressuposto básico do estudo da variação no uso da língua é o de que a heterogeneidade linguística, tal como a homogeneidade, não é aleatória, mas regulada, governada por um conjunto de regras" (NARO, 2013, p. 15). Se à Sociolinguística cabe a preocupação com a heterogeneidade e à gramática normativa cabe a responsabilidade de homogeneizar o uso, padronizando-o, significa, então, que a aleatoriedade a que se refere Naro (2013) se aplica a ambas. É neste ponto que muitos compêndios de normas se amparam justificadamente: a homogeneidade também pode ser explicada. Nesse caso, a recorrência à etimologia, à diacronia e ao conhecimento da língua latina é bastante comum, porquanto o estudo gramatical, ao que parece, também não é aleatório, apesar de padronizador.

Bagno (2007b) explica que o fenômeno fonético que motiva a transformação do $L$ em $R$ em encontros consonantais, denominado rotacismo, tem fundamentação na própria origem da língua portuguesa, não significando ignorância ou atraso mental dos falantes. Logo, palavras como "chicrete" e "praca" são um fenômeno existente no português não padrão, mais relacionado 
a quem fala do que àquilo que é falado. Para Bagno (2007b, p. 43), "neste caso específico, o preconceito lingüístico é decorrência de um preconceito social".

Nessa linha de raciocínio, é preciso ressaltar que a língua portuguesa está sujeita "a uma série de restrições que fazem com que cadeias do tipo de a casa sejam perfeitamente normais enquanto outras cadeias do tipo de casa $a$, por exemplo, não sejam usuais" (NARO, 2013, p. 15), e que algumas cadeias vocabulares são praticamente impossíveis, sendo denominadas restrições categóricas. Dessa forma, fatores linguísticos condicionam as estruturas de que se valem os falantes e, considerando que a língua também varia, condicionada por fatores extralinguísticos, tais como origem geográfica, status econômico, grau de escolarização, idade, sexo, mercado de trabalho, etc., isso explica por que a língua comporta um feixe de variedades que constroem sua riqueza de usos, inclusive a norma-padrão. Consoante Bagno (2007a, p. 44), "as pesquisas linguísticas empreendidas no Brasil têm mostrado que o fator social de maior impacto sobre a variação linguística é o grau de escolarização que, em nosso país, está muito ligado ao status socioeconômico".

Partindo dessa citação, talvez se possa apontar um dos mitos, mas não totalmente, mais comuns: o de que o status econômico está intrinsecamente relacionado ao conhecimento da norma gramatical. Com efeito, não se pode negar que os fundamentos gramaticais são valorizados como forma de distinção, já que mormente é o que se ensina nas escolas. Na verdade, o que se pretende pontuar é que, embora não contemplado como conteúdo escolar, o tratamento sociolinguístico é assaz relevante, visto que não despreza a variedade padrão; pelo contrário, a orientação é a de que se considerem funcionais todas as variedades linguísticas, inclusive a padrão. É patente, contudo, que essa não é preocupação precípua dos compêndios que definem como normativos. Aliás, como esperar comportamento distinto de uma obra que assim é caracterizada? Simples. Não se espera. Os compêndios normativos não se pretendem amplos em outro sentido que não seja o de padronizar, o que não parece irrelevante em determinados momentos da vida. O conhecimento da norma é importante, mas não esgota a amplitude social da língua, que é social porque se constrói entre as comunidades linguísticas, ou seja, a coletividade.

Nesse rumo, a Sociolinguística oferece um campo amplo investigativo capaz de abarcar vários olhares sobre a fala do indivíduo (principalmente), sem, no 
entanto, excluir a questão da escrita de suas preocupações. Ainda que a variação seja seu objeto de estudo precípuo, exclusão e mobilidade sociais, e preconceito linguístico são assuntos de interesse dessa subárea da Linguística, a qual considera a língua como heterogênea, estando condicionada a estruturas que podem ser quantificadas e explicadas (MOLLICA, 2013).

Por fim, vale registrar que à Sociolinguística cabe "investigar o grau de estabilidade ou mutabilidade da variação, diagnosticar as variáveis que têm efeito positivo ou negativo sobre a emergência dos usos linguísticos alternativos e prever seu comportamento regular e sistemático" (MOLLICA, 2013, p. 11). Tal preocupação com a variação emana de Labov (2008) e de seus estudos variacionistas, assim como a relevância da quantificação de dados linguísticos, considerando os fatores que condicionam a língua.

\section{O ESTUDO VARIACIONISTA DE LABOV}

Considerado o pai da Teoria da Variação, William Labov preocupou-se, inicialmente, com a motivação social da mudança sonora na ilha de Martha's Vineyard, no estado americano de Massachussetts. Para ele, caso se correlacionasse o complexo padrão linguístico com diferenças na estrutura social, seria possível "isolar os fatores sociais que incidem diretamente sobre o processo linguístico" (LABOV, 2008, p. 19). Eis aí uma das possíveis explicações sobre o fato de que língua e sociedade são intimamente interligadas, valendo, a propósito, a seguinte afirmação do estudioso: "por vários anos, resisti ao termo sociolinguística, já que ele implica que pode haver uma teoria ou prática linguística bem-sucedida que não é social" (LABOV, 2008, p. 13). Nesse ponto, percebe-se que a intenção de Labov não se restringia à quantificação de dados sem um propósito definido, mas tencionava desvelar os fatores sociais em relação ao processo linguístico, uma vez que "não se pode entender o desenvolvimento de uma mudança linguística sem levar em conta a vida social da comunidade em que ela ocorre" (LABOV, 2008, p. 21).

Ao escolher a ilha de Martha's Vineyard como comunidade de fala para desenvolver seus estudos sobre mudança fonética, os quais constituíram a sua dissertação de mestrado, sob orientação do professor Uriel Weinreich, Labov (2008) registra que a independência da comunidade, a separação do continente 
americano por cerca de cinco quilômetros e as complexidades geográfica e social (inclusive por se tratar de uma ilha de veraneio) formaram o pano de fundo para sua investigação. Quando iniciou a seleção das variáveis ${ }^{3}$, o estudioso baseou-se em três propriedades úteis e na existência de critérios contraditórios:

Primeiro, queremos um item que seja frequente, que ocorra tão reiteradamente no curso da conversação natural espontânea que o comportamento possa ser mapeado a partir de contextos não estruturados e de entrevistas curtas. Segundo, deve ser estrutural: quanto mais integrado o item estiver num sistema mais amplo de unidades funcionais, maior será o interesse linguístico intrínseco do nosso estudo. Terceiro, a distribuição do traço deve ser altamente estratificada: ou seja, nossas explorações preliminares devem sugerir uma distribuição assimétrica num amplo espectro de faixas etárias ou outros estratos ordenados da sociedade. Existem alguns critérios contraditórios, que nos empurram para direções diferentes. Por um lado, gostaríamos que o traço fosse saliente, tanto para nós quanto para o falante, a fim de estudar as relações diretas entre atitudes sociais e comportamento linguístico. Mas, por outro lado, valorizamos a imunidade contra a distorção consciente, o que simplifica muito o problema da confiabilidade dos dados (LABOV, 2008, p. 26).

Selecionadas as variáveis a partir dessas propriedades, Labov concebeu um modelo de entrevista a fim de recolher exemplos para seu estudo dos ditongos "/au/, como em house, e /ay/, como em right" (TARALLO, 1999, p. 13) na ilha de Martha's Vineyard. Esse modelo era constituído de: um questionário lexical cujas perguntas se concentravam nas palavras que continham os ditongos que eram objeto do estudo; de perguntas acerca de juízos de valor, com o intuito explorar a orientação social do informante, suscitando respostas que continham as formas dos ditongos e propiciando um rica coleta; e um texto para leitura especial a título de teste de habilidade. Após as transcrições dos dados originais e a organização sistemática das variáveis (como sexo e idade), Labov concluiu que "a variante conservadora, não-padrão e estigmatizada é a forma lingüística mais forte dentro da comunidade" (TARALLO, 1999, p. 14), uma vez que

Os habitantes da ilha começaram a ressentir a invasão dos veranistas e a exploração econômica decorrente: assim, atitudes lingüísticas são as armas usadas pelos residentes para demarcar seu espaço, sua identidade cultural, seu perfil de comunidade, de grupo social separado. A tendência ao exagero da forma conservadora é ainda mais acentuada entre os jovens da comunidade que, após um tempo de permanência no continente, voltaram e se estabeleceram na ilha. [...] a língua poder ser um fator extremamente importante na identificação de grupos, em sua configuração, como também uma 
possível maneira de demarcar diferenças sociais no seio de uma comunidade (TARALLO, 1999, p. 14).

Apesar da conclusão a que chegou, Labov $(2008$, p. 61) reconhece que o estudo realizado na ilha de Martha's Vineyard encontrou limitações tanto porque a variável principal não era saliente (ou seja, os ditongos não se sobressaíam nas análises) quanto porque o tamanho reduzido da amostra (ou seja, a população da ilha) "tornou impraticável explorar com profundidade a reação subjetiva dos falantes nativos aos ditongos". Além disso, várias mudanças foram promovidas na estrutura da entrevista à proporção que os estudos progrediam. Por isso, Labov (2008) considera que os estudos posteriormente realizados na cidade de Nova lorque, trabalho da tese de seu doutorado, foram mais refinados para a compreensão do mecanismo de mudança linguística, ainda que a abordagem básica tenha sido articulada nos mesmos moldes de Martha's Vineyard.

Quanto à tese construída a partir de dados coletados em novembro de 1962, em determinadas lojas de departamentos da cidade de Nova lorque, Labov (2008. p. 64) tinha a intenção de testar empiricamente se a variável linguística representada pela consoante $[r]$ em posição pós-vocálica, quando pronunciada pelos falantes, poderia ser "um diferenciador social em todos os níveis da fala" da cidade, uma vez que, ao não se pronunciar o /-r/, revelava-se uma marca do falar nova-iorquino; logo, pronunciando-o, isso poderia representar uma marca de diferenciação social. Além disso, pretendia o estudioso testar se os "eventos de fala rápidos e anônimos poderiam ser usados como base para um estudo sistemático da língua". Esse trabalho, conhecido como A estratificação social do inglês em Nova lorque ${ }^{4}$, foi realizado em três lojas conforme o status e a localização, com o objetivo de testar a estratificação social dos vendedores. As lojas escolhidas foram a Saks Fifth Avenue, a Macy's e a S. Klein. Sobre a hipótese a ser testada, Labov (2008) explica:

Uma vez que o produto da diferenciação e da avaliação social - por menor que seja - revela a estratificação social dos empregados das três lojas, a hipótese prevê o seguinte resultado: vendedores da loja de status mais alto vão apresentar os valores mais altos de (r); os da loja de status médio vão apresentar valores intermediários de (r); e os da loja de status mais baixo vão apresentar os valores mais baixos. Se tal resultado se verificar, a hipótese terá sido confirmada em proporção ao rigor do teste (LABOV, 2008, p. 66). 
Em vez de gravar as entrevistas, como havia feito em Martha's Vineyard, Labov decidiu ir às três lojas e anotar as pronúncias que ouvia. Lá perguntava aos vendedores, como se cliente fosse, onde se localizava o departamento de sapatos femininos, aguardando a sabida resposta: "no quarto andar" (fourth floor, em inglês). Assim, dois contextos fônicos da pronúncia de /-r/ poderiam ser observados, ambos em posição pós-vocálica: um no meio da palavra; outro no final. Para obter dois estilos distintos de fala (um mais casual e outro mais monitorado), Labov repetia a pergunta, fingindo não ouvi-la da primeira vez. Assim, o vendedor respondia enfaticamente. Após proceder da mesma forma nas três lojas selecionadas e categorizar as ocorrências de /-r/, Labov pôde perceber que "os usos linguísticos são diferenciados de acordo com as estratificações sociais" (MENDES, 2013, p. 123), já que sua hipótese inicial havia se comprovado.

Segundo Mendes (2013, p. 124), "padrões de uso numa comunidade de falantes podem ser depreendidos pelo sociolinguista através de distribuição de variantes, quantitativamente analisadas". Como esse entendimento emana das lições de Labov, acaba por reforçar que a quantificação e a análise de dados sociais com base nas ocorrências têm grande importância para a Teoria da Variação.

\section{O MÉTODO SOCIOLINGUÍSTICO DE PESQUISA}

Variação e mudança são, consoante Santos (2009), elementos que fazem parte da natureza das línguas vivas, logo a pesquisa variacionista de Labov (2008) encontra nicho fértil de variedades na língua portuguesa. Exemplos de diferentes formas linguísticas que exprimem uma mesma realidade podem ser resgatados de diversos cantos do país e comparados com outros a fim de demonstrar a heterogeneidade linguística e a diversidade de falares: enquanto no Maranhão se diz xícara de café com leite, em São Paulo, diz-se pingado (SANTOS, 2009).

A fim de entender como se estrutura uma investigação em Sociolinguística, é preciso explanar, mesmo de forma breve, sobre a pesquisa variacionista. Por se tratar de uma pesquisa empírica que visa coligir material que será submetido à análise para a testagem de uma hipótese, a pesquisa variacionista deve inicialmente se preocupar com a observação do comportamento do homem, abandonando a tentação de confiar na própria intuição do pesquisador, bem 
como de se basear em exemplos construídos por ele próprio (MONTEIRO, 2002). Além disso, é preciso evitar que a presença do pesquisador possa interferir na naturalidade da situação de comunicação, para que a coleta dos dados se dê fora de um ambiente monitorado, escapando, assim, do denominado "paradoxo do observador".

Sobre esse assunto, Tarallo (1999) sugere como primeira alternativa que o pesquisador não participe de forma direta da situação de comunicação, mas, como em Sociolinguística "sua participação direta na interação com os membros da comunidade é [...] uma necessidade imposta pela própria orientação teórica" (TARALLO, 1999, p. 20), o pesquisador deve coletar os dados, gravando-os em situação natural de comunicação linguística e reunindo uma grande quantidade de material que possua boa qualidade sonora, tentando neutralizar ao máximo sua própria presença e a do gravador de áudio. Uma boa opção para que se alcance tal neutralização é que o pesquisador se mostre interessado em conhecer os problemas e peculiaridades da comunidade de falantes. Assim, com o intuito de que o falante não monitore seu modo de falar, "a palavra 'língua' deverá ser evitada a qualquer preço" (TARALLO, 1999, p. 21).

Ultrapassado esse primeiro entrave no que diz respeito à naturalidade do entrevistado, o entrevistador pode formular roteiros de perguntas, a fim de controlar o rumo da conversa, provocando narrativas de experiência pessoal, já que os estudos "têm demonstrado que, ao relatá-las, o informante está tão envolvido emocionalmente com o que relata que presta o mínimo de atenção ao como. E é precisamente esta a situação natural de comunicação almejada pelo pesquisador-sociolingüista" (TARALLO, 1999, p. 22). Vale lembrar aqui que Labov (2008), tentando neutralizar sua presença, passou-se por cliente das três lojas de departamentos onde coletou os dados para a elaboração do trabalho que visava à testagem da hipótese relativa à estratificação social do inglês na cidade de Nova lorque.

Passada a fase da coleta de dados, o pesquisador, ao selecionar a comunidade de fala e os informantes, deve, dentre outros procedimentos: 1 . evitar esclarecer que o objetivo da pesquisa é o estudo da língua, para não prejudicar o comportamento dos informantes; 2 . esclarecer que, devido à natureza pessoal da gravação, esta pode ser inutilizada na presença do entrevistado; 3. minimizar o efeito da sua presença a fim de não afetar o 
comportamento sociolinguístico natural do informante; 4. utilizar o critério da amostragem aleatória para selecionar informantes em uma grande comunidade de fala, com o objetivo de garantir a chance de entrevista a todos os membros da comunidade; 5 . estabelecer parâmetros rígidos para selecionar os informantes; 6 . dimensionar o tamanho da amostra a depender da quantidade de ocorrências das variáveis, ou seja, determinar uma amostragem maior quando houver menos ocorrência e menor quando as ocorrências forem abundantes (LABOV, 2008).

Além disso, é preciso tornar representativa a amostragem da comunidade de fala, dividindo os dados em células de acordo com as variáveis selecionadas, tais como sexo, classe social, idade, etc., para que, ao proceder ao tratamento estatístico, as ocorrências sejam categorizadas de forma que permitam a interpretação cuidadosa dos resultados e a confirmação ou não da hipótese, possibilitando ao sociolinguista a descrição e explicação dos "significados sociais correlatos a certos usos linguísticos" (VIOTTI, 2013, p. 113). Dessa forma, nota-se como a pesquisa variacionista pode fornecer subsídios para a análise dos fatos linguísticos e dos sociais, correlacionado-os após uma minuciosa investigação.

A partir do exposto, percebe-se como o conhecimento do método específico utilizado na pesquisa é de grande relevância, uma vez que a estruturação do pensamento varia de ciência para ciência. As especificidades científicas devem ser consideradas na abordagem dos fenômenos sob pena de se descaracterizar um procedimento reputado típico e próprio, conquanto, a todo tempo, surjam novas possibilidades metodológicas a partir outras pré-existentes. De todo modo, a criação de novos tratamentos metodológicos pressupõe, via de regra, o reconhecimento dos antigos, razão pela qual se considera necessária a compreensão dos mecanismos e dispositivos que regem a metodologia da Sociolinguística.

\section{CONSIDERAÇÕES FINAIS}

Diante da exposição das ideias dos autores modernos que retomam os estudos de William Labov, pôde-se chegar a conclusões que devem ser ainda mais discutidas e refletidas posteriormente, dada a importância do tratamento da variação e da questão social inerente à língua. 
A princípio, percebe-se que a Sociolinguística nasceu e se desenvolveu em um propício ambiente interdisciplinar, em que as áreas do conhecimento se inter-relacionavam sem que, entretanto, rompessem as fronteiras que as definiam como disciplinas. Com a evolução constante dos estudos sociolinguísticos, fica ainda mais evidente a relação existente entre a linguagem e a sociedade, visto que é apenas no contexto social que se pode verificar a diversidade inerente aos sistemas linguísticos. Isso ocorre porque a língua, como sistema heterogêneo que é, comporta a diversidade e mudança que, com efeito, podem ser identificadas por meio da análise das situações reais de uso, como o fez William Labov em Martha's Vineyard e em Nova lorque.

Além disso, nota-se que o espaço importante que a quantificação das variantes linguísticas ocupa na identificação e na análise dos padrões de uso. A Teoria da Variação, proposta e aplicada por Labov, não é, portanto, apenas um amontoado de gráficos e números sem função definida, mas um instrumento de investigação social dos fatos linguísticos. Tanto Labov quanto os autores modernos entendem a língua como um sistema heterogêneo, mas ordenado e constituído por elementos que variam a depender da situação em que são manejados. Nesse ponto, além de outros mais, tais estudiosos convergem no entendimento da dimensão sociolinguística como muito mais do que mera quantificação.

Vale ressaltar, nesse momento, que a Sociolinguística emerge e se desenvolve como uma ciência que abarca objetos múltiplos, ainda que a variação linguística seja seu escopo principal, especialmente a relacionada à fala, mesmo que a escrita não seja dispensada. Além disso, temas como mudança e preconceito linguísticos, bem como mobilidade e exclusão sociais, são afetos aos estudos sociolinguísticos, já que envolvem situações reais de uso da língua, ou seja, um contexto social próprio.

Assim sendo, como ciência interdisciplinar, a Sociolinguística é um ramo fértil da Linguística, ou é a própria Linguística, com diria Labov, uma vez que não se pode conceber uma ciência da linguagem que desconsidere o que de social há na língua. Por isso, merece atenção e aprofundamento teórico e prático a fim de que fique ainda mais claro que a língua é tão heterogênea quanto o povo que dela faz uso. 


\title{
The sociolinguistics and the issue of variation: a general look
}

\begin{abstract}
This theoretical research objectives to analyze the contributions of Sociolinguistics in relation to aspects of variational, reflecting about the emergence of this discipline, including its research methods, and language treatment as a social practice, making use, for this, the joint between the various authors who study the subject, especially William Labov, father of Variational Theory. It is a trail of a general overview from which we discuss the issues that concern the relationship between language and society. With this, we intend to provide a introductory look about the Sociolinguistics in general to the beginners students.
\end{abstract}

KEYWORDS: Linguistics. Sociolinguistics. Linguistic variation. 


\section{NOTAS}

Por se tratar de um assunto demasiado amplo e que merece o devido aprofundamento, não se pretende tratar, neste capítulo, sobre os pontos de divergência entre a gramática normativa e a Sociolinguística.

${ }^{2}$ Variação e mudança linguísticas são conceitos distintos. Segundo Mendes (2013, p. 114), "a variação é um fato observado nos seus diferentes subsistemas". Um exemplo disso seriam as diversas possibilidades de pronúncia da consoante "d", o que se encaixaria no nível fonético/fonológico da língua. Já a mudança se relaciona, de acordo com Viotti (2013), às incontáveis modificações por que passa a língua durante o seu desenvolvimento. A título de exemplo de mudança linguística, Viotti $(2013$, p. 138) cita o percurso histórico do "pronome 'você', a partir da forma de tratamento 'vossa mercê', passando por 'vossemecê' e 'vosmecê' até chegar à forma atual".

${ }^{3}$ A variável é o conjunto de variantes linguísticas. As variantes podem ser padrão ou não padrão, conservadoras ou inovadoras, estigmatizadas ou de prestígio, sendo que, em geral, a variante considerada padrão é, ao mesmo tempo, conservadora e aquela que goza do prestígio na comunidade. As variantes inovadoras, por seu turno, são quase sempre não padrão e estigmatizadas pelos membros da comunidade.

${ }^{4}$ Originalmente chamado The Social Stratification of English in New York City.

${ }^{5}$ Optou-se aqui pelo vocábulo "conversa" porque o entrevistador deve, tanto quanto possível, evitar que o entrevistado perca a naturalidade ao fornecer os dados para análise.

\section{REFERÊNCIAS}

ALKMIM, Tânia Maria. Sociolingüística - Parte I. In: MUSSALIM, F. \& BENTES, A. C. (ed.). Introdução à Lingüística. São Paulo: Cortez, 2001.

BAGNO, Marcos. Nada na língua é por acaso: por uma pedagogia da variação linguística. 1ạ ed. São Paulo: Parábola Editorial, 2007a.

BAGNO, Marcos. Preconceito linguístico: o que é, como se faz. 49a ed. São Paulo: Edições Loyola, 2007b.

BELINE, Ronald. A variação linguística. In: FIORIN, J. L. (org.). Introdução à Linguística - Objetos teóricos. 6a ed. São Paulo: Contexto, 2014.

CALVET, Louis Jean. Sociolingüística: uma introdução crítica. 2a ed. São Paulo: Parábola, 2002.

CAMACHO, Roberto Gomes. Sociolingüística - Parte II. In: MUSSALIM, F. \& BENTES, A. C. (ed.). Introdução à Lingüística. São Paulo: Cortez, 2001. 
LABOV, William. Padrões sociolinguísticos. São Paulo: Parábola Editorial, 2008.

LYONS, John. Lingua(gem) e lingüistica: uma introdução. Rio de Janeiro: LTC, 2011.

Recebido: 29 ago. 2015

Aprovado: 22 mar. 2017

DOI: $10.3895 /$ rl.v19n25.3168

Como citar: OLIVEIRA, Thiago Soares de. A Sociolinguística e a questão da variação: um panorama geral.

R. Letras, Curitiba, v. 19, n. 25, p. 01-18, jan./jun. 2017. Disponível em: <https://periodicos.utfpr.edu.br/rl>.

Acesso em: XXX.

Direito autoral: Este artigo está licenciado sob os termos da Licença Creative Commons-Atribuição 4.0 Internacional.

(c) (i) 